Rio de Janeiro. Ano 15. Volume 22. Número 3. Setembro a Dezembro de 2021

Periódico Quadrimestral da Pós-Graduação Stricto Sensu em Direito Processual da UERJ

Patrono: José Carlos Barbosa Moreira (in mem.). ISSN 1982-7636. pp. 631-655 www.redp.uerj.br

\title{
VIOLÊNCIA DOMÉSTICA E PROCESSO PENAL CONSENSUAL: EXAME CRÍTICO DA INAPLICABILIDADE DAS SOLUÇÕES CONSENSUAIS PREVISTAS NA LEI No 9.099/95 ${ }^{1}$
}

DOMESTIC VIOLENCE AND CONSENSUAL CRIMINAL PROCEDURE: CRITICAL ANALYSIS OF THE INAPPLICABILITY OF THE SOLUTIONS ENSHRINED IN LAW 9,099/95

Luisa Angélica Mendes Mesquita Mestranda em Direito Penal pela Faculdade de Direito da Universidade de São Paulo, LL.M. por Georgetown University Law Center, bacharela em Direito Francês pela Université de Lyon 3 e bacharela em Direito pela Universidade de São Paulo. Advogada. São Paulo/SP. E-mail: luisa.mesquita@usp.br

Brenno Gimenes Cesca Mestre e doutorando em Direito Processual Penal pela Universidade de São Paulo. Professor e juiz formador da Escola Paulista de Magistratura e da Escola Nacional de Formação e Aperfeiçoamento de Magistrados e juiz de direito. São Paulo/SP. E-mail: brennogc@gmail.com.

RESUMO: O presente trabalho propõe-se ao exame crítico do tratamento conferido à violência doméstica no âmbito processual penal ante a inaplicabilidade da Lei $n^{\circ}$ 9.099/95 imposta pela Lei Maria da Penha (Lei n ${ }^{\circ} 11.340 / 2006$ ). Para tanto, inicialmente, expõe-se brevemente o panorama internacional e nacional que embasou a política criminal e a racionalidade legislativa existente na Lei Maria da Penha. Posteriormente, apresenta-se o problema condutor da pesquisa: a inaplicabilidade da Lei $\mathrm{n}^{0}$ 9.099/95 confirmada pela jurisprudência e em consonância com a política criminal que embasou a opção legislativa.

\footnotetext{
${ }^{1}$ Artigo recebido em 03/12/2020 e aprovado em 13/04/2021.
} 
Por fim, busca-se analisar a referida escolha à luz do que vem a ser processo penal consensual para, posteriormente, tecer as devidas críticas.

PALAVRAS-CHAVE: Lei Maria da Penha. Lei dos Juizados Especiais Criminais. Feminismo. Justiça consensual. Simbolismo penal.

ABSTRACT: This article aims to critically examine the treatment given to domestic violence in criminal procedure in light of the inapplicability of Law 9,099/95 imposed by the Maria da Penha Act (Law 11,340/2006). Hence, firstly, we briefly present the international and national panorama that underlines the criminal justice policy and legislative rationality enshrined in the Maria da Penha Act. Then, we set out the research problem: the inapplicability of Law 9,099/95, confirmed by precedents and in line with the criminal justice policy that underpinned such legislative option. Finally, we analyze this choice in view of consensual justice doctrine to, then, point out the applicable critiques.

KEYWORDS: Maria da Penha Act. Special Criminal Courts Act. Feminism. Consensual justice. Criminal sybolism.

SUMÁRIO. INTRODUÇÃO. 1. CONTEXTO HISTÓRICO E LEGISLATIVO DO COMBATE À VIOLÊNCIA DOMÉSTICA. 1.1. A insurgência da voz feminina. 1.2. Contexto internacional e racionalidade legislativa. 1.3. Lei Maria da Penha. 1.3.1. Aspectos materiais e processuais penais da Lei Maria da Penha: direito penal simbólico e críticas cabíveis. 2. A INAPLICABILIDADE DA LEI $\mathrm{N}^{\circ}$ 9.099/95 PARA CASOS DE VIOLÊNCIA DOMÉSTICA. 2.1. Exame crítico da política criminal adotada. 2.2. O entendimento consolidado pelo Supremo Tribunal Federal e pelo Superior Tribunal de Justiça. 3. A OPÇÃO LEGISLATIVA À LUZ DO PROCESSO PENAL CONSENSUAL E AS CRÍTICAS CABÍVEIS. 3.1. Processo penal consensual e Lei ${ }^{\circ}$ 9.099/95. 3.2. Críticas à opção legislativa da Lei Maria da Penha. CONCLUSÕES. Referências

\section{INTRODUÇÃO}


O presente artigo destina-se ao exame crítico do tratamento conferido à violência doméstica no âmbito processual penal. Para tanto, de início, deve-se expor brevemente o panorama acerca do contexto internacional e nacional que embasou a política criminal e a racionalidade legislativa existente na Lei Maria da Penha (Lei $\mathrm{n}^{\circ}$ 11.340/2006). Nesse sentido, a Lei $\mathrm{n}^{\mathrm{o}}$ 11.340/2006 é considerada como marco legislativo pioneiro e revolucionário no enfrentamento à violência doméstica impondo novos parâmetros extralegais e legais.

Não obstante, este trabalho se restringe a analisar somente as inovações processuais penais trazidas pela Lei. É a partir dessa observação que se identifica o problema condutor desta pesquisa, no capítulo 2, isso é: a opção legislativa pela inaplicabilidade da Lei $\mathrm{n}^{\circ}$ 9.099/95, confirmada pela jurisprudência do Supremo Tribunal Federal e do Superior Tribunal de Justiça e em consonância com a política criminal que embasou o instrumento legal.

Nesse ponto, no capítulo 3, deve-se realizar o exame crítico de tal opção por meio do estudo da racionalidade fundante tanto da Lei n ${ }^{\circ}$ 9.099/95 quanto da Lei Maria da Penha a fim de estabelecer o diagnóstico da situação atual do enfrentamento da violência doméstica e indicar, brevemente, alternativa viável para a questão.

\section{CONTEXTO HISTÓRICO E LEGISLATIVO DO COMBATE À VOILÊNCIA DOMÉSTICA $^{2}$}

Fruto de séculos de uma cultura patriarcal que passou a ser efetivamente compreendida e enfrentada há menos de 150 anos, a violência contra a mulher não apenas foi internalizada e aceita, mas também reiterada e perpetuada até os dias atuais. Neste contexto, a violência de gênero ${ }^{3}$ se trata de uma imposição de força com a finalidade de dominação/exploração, isto é, como resultado de uma assimetria hierárquica.

\footnotetext{
2 Para fins deste trabalho, adota-se violência doméstica como sinônimo de violência de gênero. Não obstante, sabe-se que a violência doméstica não é restrita somente às mulheres, tanto que a Lei Maria da Penha acabou por recepcionar a proteção às mulheres transsexuais e outras pessoas no âmbito doméstico familiar. Ademais, a violência de gênero é mais abrangente que a violência doméstica, isso é, a violência de gênero engloba a violência doméstica; a violência física, sexual e psicológica contra a mulher. Ainda assim, usa-se o panorama de violência de gênero para contextualizar a violência doméstica.

${ }^{3}$ Há que se indicar diversas formas de violência contra à mulher: doméstica, física, sexual e psicológica. A primeira é a mais frequente pois ocorre no ambiente privado, local em que a mulher apresenta maior
} 


\subsection{A insurgência da voz feminina}

Já no século XVIII, houve iniciativas pontuais pleiteando a defesa da mulher e o combate à discriminação entre homens e mulheres pelas suas simples condições de gênero. Pretendia-se defender o papel das mulheres na sociedade enquanto cidadãs por meio do acesso à educação no contexto das revoluções burguesas. ${ }^{4}$

A primeira onda do movimento feminista, contudo, surgiu em meados do século XIX, quando da busca pelo direito ao voto e educação por meio das sufragistas (ou suffragettes). Isso porque, somente nesse momento as postulações relacionadas aos direitos das mulheres começaram a acontecer de forma mais organizada por meio da criação de entidades coletivas. Tais mulheres requeriam reformas de cunho educativo, político e social, mas, sobretudo, o direito ao voto. ${ }^{5}$

Depois de atingir as aspirações sufragistas ${ }^{6}$, chegou-se à segunda fase do feminismo, iniciado na segunda metade do século XX, quando houve uma maior publicização da

vulnerabilidade. Deste modo, acaba sendo a maneira mais comum e invisível de violência. A violência física consiste na ação de agredir provocando desde pequenas lesões até, às vezes, a morte em razão, na maioria das vezes, do rompimento na relação hierárquica estabelecida entre os gêneros. Já a violência psicológica ou agressão emocional caracteriza-se por recriminações constantes como: desvalorização profissional, rejeição, depreciação, discriminação, humilhação, desrespeito e punições exageradas que podem ser tão ou mais prejudiciais do que as outras formas de violência, vez que deixa sequelas que destroem a autoestima da mulher, expondo-a a um risco mais elevado de sofrer problemas psiquiátricos, como depressão, fobia, estresse póstraumático, tendência ao suicídio e consumo abusivo de álcool e drogas. Por fim, a violência sexual advém do pensamento de que o ato sexual é dever conjugal em que a mulher tem a obrigação de ter relações sexuais sendo tratada como objeto de desejo masculino. Veja-se: BORIN, Thaisa Belloube. Violência doméstica contra a mulher: percepções sobre violência em mulheres agredidas. Dissertação de mestrado em Psicologia apresentada à Faculdade de Filosofia, Ciências e Letras de Ribeirão Preto da Universidade de São Paulo. Teses USP. Disponível em: <http://www.teses.usp.br/teses/disponiveis/59/59137/tde-30092008-

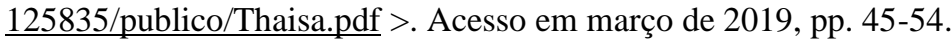

${ }^{4}$ GERHARD, Ute. Sobre a liberdade, igualdade e dignidade das mulheres: o direito "diferente" de Olympe de Gouges. In: BONACCHI, Gabriela; GROPPI, Angela (Orgs). O dilema da cidadania: direitos e deveres das mulheres. São Paulo: Editora da Universidade Estadual Paulista, 1995, pp. 52-3.

${ }^{5}$ ALVES, Branca Moreira; PITANGUY, Jacqueline. O que é feminismo. Coleção Primeiros Passos. São Paulo: abril Cultural/Brasiliense, 1981, pp. 44-6.

${ }^{6}$ A luta feminina pelo direito ao voto foi dura, tendo algumas sufragistas sido presas e torturadas quando se manifestavam publicamente. Os primeiros países a reconhecerem o direito ao voto às mulheres foram Nova Zelândia (1893), Austrália (1902) e Finlândia (1906). 
violência contra a mulher seja física, institucional, emocional e/ou psicológica visando políticas públicas e enfrentamentos jurídico-legais ${ }^{7}$.

A partir da década de 90, inicia-se a terceira onda em que se passa a reivindicar as distinções entre as próprias mulheres. Isto é, são levantadas críticas dentro do próprio movimento feminista, demonstrando que o discurso universal às mulheres seria excludente, pois as opressões atingem as diversas mulheres de modos diferentes. Busca-se desconstruir a categoria de "mulher" enquanto um sujeito coletivo unificado para reivindicar as especificidades das mulheres e suas variadas demandas ${ }^{8}$.

No Brasil tais fases também ocorreram, mas tardiamente. A primeira onda do feminismo brasileiro ocorreu somente no início do século $\mathrm{XX}$ devido à luta pelo direito ao voto feminino9 ${ }^{9}$ o qual somente foi conquistado em 1932, quando do Código Eleitoral Provisório (Decreto no 21.076), e contemplado na Constituição Brasileira de 1934.

Em sua segunda fase, o movimento feminista brasileiro focou, primordialmente, na exposição da violência contra a mulher no espaço público, exigindo por parte do Estado políticas públicas de enfrentamento à violência. Desde 1960, passaram a ser reivindicados abrigos, assistência jurídica especial à população feminina e atendimento policial. Com isso, a partir da década de 80 , os movimentos de mulheres e das feministas começaram a desenvolver ações para visibilizar a violência contra as mulheres e a importância do seu combate $^{10}$. A despeito das iniciativas governamentais, remanesceram dificuldades para o combate da violência às mulheres no âmbito doméstico em razão da ausência de leis específicas.

\footnotetext{
${ }^{7}$ MESQUITA, Luisa Angélica Mendes. Violência de gênero e direito penal: tipificação do feminicídio e possíveis respostas penais. Revista Eletrônica de Direito Penal e Política Criminal - UFRGS, v. 6, n. 2, dezembro de 2018, p. 173.

${ }^{8}$ BUTLER, Judith. Problemas de gênero: feminismo e subversão da identidade. Tradução Renato Aguiar. Rio de Janeiro: Civilização Brasileira, 2003, pp. 179-83.

${ }^{9}$ Em 1910, houve a fundação do Partido Republicano Feminino, no Rio de Janeiro, por Leolinda Daltro. Vale mencionar também Berta Lutz, outra importante militante que reuniu mulheres da burguesia na busca pelo direito ao voto.

${ }^{10}$ Nesse sentido, surgiu o SOS-Mulher (entidade autônoma voltada ao atendimento jurídico, social e psicológico de mulheres vítimas de violência); as Delegacias Especializadas no Atendimento a Mulheres DEAM; o Centro de Orientação Jurídica - COJE (criado em 1986, para orientar juridicamente as mulheres informando-as sobre seus direitos e encaminhando-as para a tomada das medidas legais possíveis em caso de violência) e, posteriormente, o Centro de Convivência de Mulheres Vítimas de Violência Doméstica COMVIDA (trata-se do primeiro abrigo do país para mulheres em situação de risco em local sigiloso). Confirase SANTOS, Cecília MacDowell. Da delegacia da Mulher à Lei Maria da Penha. Absorção/tradução de demandas feministas pelo Estado. Revista Crítica de Ciências Sociais, nº 89, 2010, pp. 153-70.
} 
Por fim, na década de 90, teve início a terceira onda do feminismo brasileiro em que se começou a discutir os paradigmas estabelecidos anteriormente de modo a colocar em discussão a micropolítica e especificidades de cada grupo de mulher. Nesse contexto, vale pontuar a duplicidade, e até ambiguidade ou contradição ${ }^{11}$, de certas demandas do movimento feminista. Isto é, a referência ao movimento feminista não significa afirmar que ele seja monolítico, pois por meio dele falam diversas vozes.

\subsection{Contexto internacional e racionalidade legislativa}

Apenas a partir da década de 70, a comunidade internacional passou a ver como necessário o tratamento especial à problemática do gênero. Em 1979, aprovou-se o primeiro documento internacional de direitos humanos que aborda exclusivamente o tema da violência contra a mulher: a Convenção sobre a Eliminação de Todas as Formas de Discriminação contra a Mulher (CEDAW), ratificada pelo Brasil em 1984. A CEDAW possui considerações e disposições mais abstratas visando afirmar a igualdade de direitos do homem e da mulher e delimitar o que seria a "discriminação contra a mulher". Importa destacar que suas determinações demonstram a necessidade de mudança dos comportamentos tanto da população civil quanto do próprio Estado enquanto ente administrativo, legislativo e executivo. ${ }^{12}$

No entanto, apesar de tais importantes previsões, somente com a Conferência Mundial sobre Direitos Humanos em Viena, em 1993, a pauta de violência contra a mulher foi assumida como prioritária no contexto da proteção internacional dos direitos humanos das mulheres. Posteriormente, merecem menção ainda as Declarações e Programas de Ações

\footnotetext{
${ }^{11}$ ANDRADE, Vera Regina Pereira de. Sistema penal máximo x Cidadania mínima: códigos de violência na Era da globalização. Porto Alegre: Editora Livraria do Advogado, 2003, p. 102.

${ }^{12}$ Em seu artigo $2^{\circ}$ estipula que os Estados Partes promovam políticas destinadas a eliminar a discriminação contra a mulher por meio de "legislação apropriada" (artigo $2^{\circ}, a$ ), "medidas adequadas, legislativas e de outro caráter, com as sanções cabíveis" (artigo $2^{\circ}, b$ ), "proteção jurídica dos direitos da mulher..., por meio dos tribunais nacionais competentes e de outras instituições públicas" (artigo $2^{\circ}, c$ ), "abster-se de incorrer em todo ato ou prática de discriminação contra a mulher e zelar para que as autoridades e instituições públicas atuem em conformidade com esta obrigação" (artigo $2^{\circ}, d$ ) e também derrogar leis, regulamentos, usos e práticas que constituíam discriminação contra a mulher (artigo $2^{\circ}, f$ e artigo $2^{\circ}, g$ que traz essa mesma previsão especificamente quanto às disposições legais penais). Há ainda disposições acerca da discriminação contra a mulher na esfera política (artigo $7^{\circ}$ ); em questões que envolvam nacionalidade (artigo $9^{\circ}$ ); educação (artigo 10); emprego (artigo 11); assistência à saúde e cuidados médicos (artigo 12); na esfera econômica (artigo 13); no espaço rural (artigo 14); em matéria civil (artigo 15); em assuntos relativos ao casamento e as relações familiares (artigo 16).
} 
Revista Eletrônica de Direito Processual - REDP.

Rio de Janeiro. Ano 15. Volume 22. Número 3. Setembro a Dezembro de 2021

Periódico Quadrimestral da Pós-Graduação Stricto Sensu em Direito Processual da UERJ

Patrono: José Carlos Barbosa Moreira (in mem.). ISSN 1982-7636. pp. 631-655

www.redp.uerj.br

oriundas das principais conferências internacionais das Nações Unidas (Viena/93, Cairo/94 e Beijing/95).

Em nível regional interamericano, o primeiro instrumento específico destinado ao combate da violência de gênero foi a Convenção Interamericana para Prevenir, Punir e Erradicar a Violência contra a Mulher (Convenção de Belém do Pará) aprovada em 1994 pela Assembleia Geral da Organização dos Estados Americanos (OEA) e ratificada pelo Brasil em 1995.

A "Convenção de Belém do Pará" versa nomeadamente sobre a questão da violência contra a mulher e em seu artigo $1^{\circ}$ delimita que será entendida por violência contra a mulher: "qualquer ato ou conduta baseada no gênero, que cause morte, dano ou sofrimento físico, sexual ou psicológico à mulher, tanto na esfera pública como na esfera privada”. Deve-se mencionar o capítulo III destinado aos deveres dos Estados ${ }^{13}$, em que se encontra o artigo 8 que traz medidas específicas e prevê programas. ${ }^{14}$

Diante desses avanços no cenário internacional, diversas reformas foram feitas no âmbito interno de países visando adequar suas legislações aos padrões internacionais de direitos humanos ${ }^{15}$. Foi sob influência desse contexto que as discussões sobre formas de

\footnotetext{
${ }^{13}$ Há algumas previsões que endossam as anteriores da CEDAW e outras inovadoras e/ou mais específicas tais como: "adotar medidas jurídicas que exijam do agressor que se abstenha de perseguir, intimidar e ameaçar a mulher ou de fazer uso de qualquer método que danifique ou ponha em perigo sua vida ou integridade ou danifique sua propriedade" (artigo 7,d); "estabelecer mecanismos judiciais e administrativos necessários para assegurar que a mulher sujeitada a violência tenha efetivo acesso a restituição, reparação do dano e outros meios de compensação justos e eficazes" (artigo $7, g$ ).

${ }^{14}$ Ressaltam-se disposições como "modificar os padrões sociais e culturais de conduta de homens e mulheres, inclusive a formulação de programas formais e não formais adequados a todos os níveis do processo educacional, a fim de combater preconceitos e costumes e todas as outras práticas baseadas na premissa da inferioridade ou superioridade de qualquer dos gêneros ou nos papéis estereotipados para o homem e a mulher, que legitimem ou exacerbem a violência contra a mulher" (artigo 8, b) que, claramente, extrapolam a mera produção legal ou uma atuação restrita ao espaço do judiciário. Nesse sentido, também os artigos $8, e$ e $g$ pretendem o uso de programas educacionais e dos meios de comunicação visando a conscientização para a questão da violência contra a mulher. Além disso, o artigo 8, $d$ propõe a prestação de "serviços especializados apropriados à mulher sujeitada a violência, por intermédio de entidades dos setores público e privado, inclusive abrigos, serviços de orientação familiar, quando for o caso, e atendimento e custódia dos menores afetados".

${ }^{15}$ Em uma primeira onda de reformas, houve a descriminalização de delitos como o adultério, o rapto e a sedução, bem como a revogação do dispositivo legal que previa a extinção da punibilidade do crime pelo casamento da vítima com o autor ou com terceiro, com vistas a corrigir a institucionalização da discriminação contra a mulher contida naqueles preceitos legais. Na segunda onda foram editadas leis específicas com o objetivo de coibir atos de violência contra a mulher dentro da família, assegurando-lhe assistência e medidas protetivas. Também foi regulamentada a atuação do Estado na prevenção, no atendimento das vítimas e na persecução dos responsáveis. Nesse sentido, veja-se: MESQUITA, Luisa Angélica Mendes. Violência de gênero e direito penal: tipificação do feminicídio e possíveis respostas penais. Revista Eletrônica de Direito Penal e Política Criminal-UFRGS, v. 6, n. 2, dezembro de 2018, pp. 174-77.
} 
combate, erradicação e prevenção da violência de gênero se avolumaram e desembocaram em inovações legislativas e programas em vários países.

\subsection{Lei Maria da Penha}

Em compasso com os avanços no cenário internacional e com os anseios e conquistas no âmbito nacional, oriundos sobretudo do movimento feminista ${ }^{16}$, foi aprovada a Lei $\mathrm{n}^{\circ}$ 11.340/2006, em 7 de agosto de 2006, vulgarmente conhecida como Lei Maria da Penha ${ }^{17}$.

Internacionalmente, a Lei Maria da Penha é reconhecida como um exemplo de legislação efetiva e pioneira para o tratamento da violência doméstica contra mulheres em razão de ter recepcionado as recomendações dos tratados internacionais de direitos humanos das mulheres; de ter conceituado a violência contra mulheres como uma violência de gênero e de buscar a perspectiva de tratamento integral para a problemática (isso é, medidas assistenciais, de prevenção e de contenção da violência $)^{18}$.

Outrossim, a Lei $\mathrm{n}^{\circ} 11.340 / 2006$ definiu verdadeira mudança conceitual e operacional no tratamento das violências contra mulheres no Brasil por ter criado um sistema jurídico autônomo regido por regras próprias de interpretação, de aplicação e de execução ${ }^{19}$.

\footnotetext{
${ }^{16}$ MONTENEGRO, Marilia. Lei Maria da Penha: uma análise criminológico-crítica. $1^{\text {a }}$ ed., Rio de Janeiro: Revan, 2015, pp. 99-113.

${ }^{17}$ Maria da Penha Maia Fernandes, mulher que dá nome à lei, foi vítima de duas tentativas de homicídio por seu ex-marido, em 1983. Em 2002, após 19 anos da prática do crime, o seu ex-marido passou 2 anos preso. O caso tomou tamanho repercussão que chegou ao conhecimento da Comissão Interamericana de Direitos Humanos, órgão da Organização dos Estados Americanos (OEA) que acatou, pela primeira vez, a denúncia de um crime de violência doméstica. Confira-se: MONTENEGRO, Marilia. Lei Maria da Penha: uma análise criminológico-crítica. $1^{\mathrm{a}}$ ed., Rio de Janeiro: Revan, 2015, pp. 108-9.

18 CAMPOS, Carmen Hein de; CARVALHO, Salo. Tensões atuais entre a criminologia feminista e a criminologia crítica: a experiência brasileira. In: CAMPOS, Carmen Hein de (Org.). Lei Maria da Penha Comentada em uma perspectiva jurídico-feminista. Rio de Janeiro: Lumen Juris, 2011, p.143-172.

${ }^{19}$ No âmbito jurídico, são as inovações: a) a limitação da tutela estatal apenas para as mulheres como uma forma de instrumento normativo que busca a igualdade material; b) a não utilização da expressão "vítima", mas sim "mulheres em situação de violência doméstica" sob o argumento de que a primeira forma colocaria as mulheres na posição de "objeto" da violência, sem autonomia (ou com autonomia reduzida) e no lugar de um não-sujeito de direitos; c) a exclusão dos atos de violência doméstica do rol dos crimes considerados de menor potencial ofensivo (artigo 41); d) a previsão de a companheira ser processada nos casos de relações homoafetivas (artigo $5^{\circ}$, parágrafo único); e) inovação nas medidas cautelares de proteção havendo duas espécies de medidas, voltadas à ofendida (artigo 23) e ao agressor (artigo 22); f) criação dos juizados de violência doméstica e familiar com competência cível e penal.
} 
Diversamente de outros instrumentos, estabeleceu medidas de natureza extrapenal ${ }^{20}$ que ampliam a tutela da violência contra mulheres transcendendo os restritos horizontes penais.

\author{
1.3.1. Aspectos materiais e processuais penais da Lei Maria da Penha: direito penal \\ simbólico ${ }^{21}$ e críticas cabíveis
}

É evidente que a Lei Maria da Penha representa importante marco no que diz respeito às medidas de prevenção e de proteção da mulher. Não obstante, várias críticas podem ser feitas, principalmente no campo penal e processual penal.

De início, nota-se que a Lei apresenta uma grande carga simbólica posto que alguns dos seus artigos só repetem os direitos e garantias fundamentais já consagrados na

\footnotetext{
${ }^{20}$ Salientam-se: a) programas de longo prazo como planejamento das políticas públicas, promoção de pesquisas e estatísticas, controle de publicidade sexista; b) medidas emergenciais como a criação de cadastro de programas assistenciais governamentais nos quais as mulheres em situação de violência doméstica tenham prioridade de assistência, principalmente quando houver risco à integridade física e psicológica, e a previsão de remoção ou de afastamento do trabalho de forma prioritária quando a servidora pública é vítima ou sua integridade física ou psíquica encontra-se em risco e c) as medidas de proteção ou contenção da violência como criação de programas de atendimento ou proteção, fornecimento de assistência judiciária gratuita, possibilidade de atendimento por equipe multidisciplinar.

${ }^{21}$ Cumpre esclarecer a noção de Direito Penal simbólico ou simbolismo penal aqui adotada foi aquela exposta por Hassemer: "Não há um conceito preciso de "simbólico" e "legislação simbólica". Existe um acordo global que direciona para o fenómeno do Direito simbólico: trata-se de uma oposição entre "realidade" a "aparência", entre "manifesto" e "latente", entre o "verdadeiramente desejado" e o "realmente aplicado". "Simbólico" associa-se com engano, tanto em sentido trânsito quanto em sentido reflexivo. "Simbólico" em sentido crítico é, por conseguinte, um Direito penal no qual as funções latentes predominam sobre as manifestas [...] O Direito penal simbólico ocorre de diversas formas: por meio de um Direito penal que está menos orientado à proteção do bem jurídico do que para os efeitos políticos mais amplos como a satisfação de uma "necessidade de ação". Trata-se de um fenômeno da crise da política criminal orientado às consequências que converte o Direito penal em um instrumento político tutelador de bens jurídicos universais e delitos de perigo abstrato. Este Direito penal se relaciona às imagens de uma "insegurança global" e uma "sociedade do risco". Um Direito penal simbólico com uma função de engano que não cumpre sua tarefa política criminal e mina a confiança da população na Justiça.” (HASSEMER, Winfried. Derecho Penal Simbólico y protección de Bienes Jurídicos. Tradução livre. Santiago: Editorial Jurídica Conosur, 1995.)
} 
Constituição Federal brasileira (a exemplo os artigos $2^{\circ}$ e $\left.3^{\text {o22 }}\right)^{23}$. Igualmente simbólico é o nome vulgar atribuído à Lei uma vez que ao nomeá-la de Maria da Penha, passou-se a associar todos os casos de violência doméstica aos crimes cometidos contra Maria da Penha, enquanto, em verdade, tais crimes tendem a ser de baixa lesividade. ${ }^{24}$

No âmbito processual penal, foco deste estudo, são alvos de intensas análises o quanto disposto nos artigos 16, 41 e 42 da Lei Maria da Penha. O artigo $16^{25}$ objetifica a mulher uma vez que, sob a justificativa de sua proteção, marginaliza-se a sua capacidade de escolha, tratando-a como um sujeito indefeso, incapaz de tomar suas próprias decisões. Isso é, a vítima passa a ser considerada um acicate processual, um instrumento para mobilizar o aparato de controle e para justificar a punição estatal. ${ }^{26}$

Já o artigo $41^{27}$ vedou a aplicação da Lei dos Juizados Especiais Cíveis e Criminais (Lei $\mathrm{n}^{\circ} 9.099$, de 26 de setembro de 1995) aos crimes que envolvam violência doméstica e familiar. A racionalidade de tal dispositivo advém do intuito de evitar que os incidentes de violência doméstica continuassem sendo, majoritariamente, reduzidos ao pagamento de cestas básicas e sem a fixação de medidas protetivas como eram anteriormente. Isso porque, até a Lei Maria da Penha, os crimes de lesão corporal de natureza leve e de ameaça - os mais recorrentes nos casos de violência doméstica - eram enquadrados no conceito de infração de

22 Art. $2^{\circ}$ Toda mulher, independentemente de classe, raça, etnia, orientação sexual, renda, cultura, nível educacional, idade e religião, goza dos direitos fundamentais inerentes à pessoa humana, sendo-lhe asseguradas as oportunidades e facilidades para viver sem violência, preservar sua saúde física e mental e seu aperfeiçoamento moral, intelectual e social.

Art. $3^{\circ}$ Serão asseguradas às mulheres as condições para o exercício efetivo dos direitos à vida, à segurança, à saúde, à alimentação, à educação, à cultura, à moradia, ao acesso à justiça, ao esporte, ao lazer, ao trabalho, à cidadania, à liberdade, à dignidade, ao respeito e à convivência familiar e comunitária.

$\S 1^{\circ} \mathrm{O}$ poder público desenvolverá políticas que visem garantir os direitos humanos das mulheres no âmbito das relações domésticas e familiares no sentido de resguardá-las de toda forma de negligência, discriminação, exploração, violência, crueldade e opressão.

$\S 2^{\circ}$ Cabe à família, à sociedade e ao poder público criar as condições necessárias para o efetivo exercício dos direitos enunciados no caput.

${ }^{23}$ MONTENEGRO, Marilia. Lei Maria da Penha: uma análise criminológico-crítica. $1^{\mathrm{a}}$ ed., Rio de Janeiro: Revan, 2015, p. 53.

${ }^{24}$ MEDEIROS, Carolina Salazar l'Armée Queiroga de e MELLO, Marília Montenegro Pessoa de. Entre a "renúncia" e a intervenção penal no crime de violência doméstica contra a mulher in SANTIGO, Nestor Eduardo Araruna; BORGES, Paulo César Corrêa; SOUZA, Claudio Macedo de. (Org.). Direito penal, processo penal e constituição. Florianópolis: CONPENDI, 2014, pp. 488-514.

${ }^{25}$ Art. 16. Nas ações penais públicas condicionadas à representação da ofendida de que trata esta Lei, só será admitida a renúncia à representação perante o juiz, em audiência especialmente designada com tal finalidade, antes do recebimento da denúncia e ouvido o Ministério Público.

${ }^{26}$ MONTENEGRO, Marilia. Lei Maria da Penha: uma análise criminológico-crítica. $1^{\text {a }}$ ed., Rio de Janeiro: Revan, 2015, p. 75.

${ }^{27}$ Art. 41. Aos crimes praticados com violência doméstica e familiar contra a mulher, independentemente da pena prevista, não se aplica a Lei n ${ }^{\circ}$ 9.099, de 26 de setembro de 1995. 
Rio de Janeiro. Ano 15. Volume 22. Número 3. Setembro a Dezembro de 2021

Periódico Quadrimestral da Pós-Graduação Stricto Sensu em Direito Processual da UERJ

Patrono: José Carlos Barbosa Moreira (in mem.). ISSN 1982-7636. pp. 631-655 www.redp.uerj.br

menor potencial ofensivo ${ }^{28}$. No entanto, mais eficiente seria, então, somente restringir as possibilidades de penas alternativas como fez o artigo $17^{29}$, em que o juiz não pode aplicar a pena pecuniária, sendo, todavia, possível a aplicação de outras restritivas de direito.

Por fim, igualmente recrudescedor é o artigo $42^{30}$ que possibilitou a prisão preventiva nos casos de violência doméstica e familiar contra mulher. Tal ampliação da prisão preventiva ocorreu com a intenção de garantir a execução das medidas protetivas.

Nesse sentido, nota-se que tais dispositivos se apoiam no caráter simbólico do direito penal. Isso é, em normas penais elaboradas no clamor da opinião pública, suscitada na maioria das vezes quando da ocorrência de crimes violentos, desconsiderando as causas históricas, sociais e políticas da criminalidade, apresentando como única resposta a criação de novos e mais rigorosos comandos normativos penais ${ }^{31}$.

Diante disso, as inovações processuais penais trazidas pela Lei são as que mais evidenciam a consolidação de uma administração da justiça que se orienta por meio do direito penal simbólico, aproximando-se de movimentos político criminais maximalistas de cunho retributivista.

\section{INAPLICABILIDADE DA LEI No 9.099/95 PARA CASOS DE VIOLÊNCIA DOMÉSTICA}

Ante o contexto histórico de violência doméstica e os avanços legislativos em busca do seu combate, observou-se a construção de uma política criminal clara no sentido da maior

\footnotetext{
${ }^{28}$ CAMPOS, Carmen Hein de; CARVALHO, Salo de. Violência doméstica e Juizados Especiais Criminais: análise a partir do feminismo e do garantismo. Revista Estudos Feministas, Florianópolis, vol. 14, n. 2, pp. 409-422, mai./ago., 2006.

${ }^{29}$ Art. 17. É vedada a aplicação, nos casos de violência doméstica e familiar contra a mulher, de penas de cesta básica ou outras de prestação pecuniária, bem como a substituição de pena que implique o pagamento isolado de multa.

${ }^{30}$ Art. 42 . O art. 313 do Decreto-Lei no 3.689, de 3 de outubro de 1941 (Código de Processo Penal), passa a vigorar acrescido do seguinte inciso IV:

"Art. 313. [...]

IV - se o crime envolver violência doméstica e familiar contra a mulher, nos termos da lei específica, para garantir a execução das medidas protetivas de urgência." (NR)"

${ }^{31}$ Adota-se a visão acerca do direito penal simbólico contida no artigo Violência de gênero e direito penal: tipificação do feminicídio e possíveis respostas penais que apesar de tratar sobre tal instituto no âmbito da tipificação do feminicídio, insere-se também no contexto de violência de gênero de modo que a análise pode ser aqui aproveitada. Nesse sentido, confira-se: MESQUITA, Luisa Angélica Mendes. Violência de gênero e direito penal: tipificação do feminicídio e possíveis respostas penais. Revista Eletrônica de Direito Penal e Política Criminal-UFRGS, v. 6, n. 2, dezembro de 2018.
} 
repressão à violência doméstica e à violência de gênero. Nessa toada, a Lei Maria da Penha trouxe diversas inovações penais e processuais penais, dentre elas o artigo 41, que afastou as situações de violência doméstica e familiar do âmbito dos Juizados Especiais Criminais, impedindo a aplicação da Lei no 9.099/95, levando-as para os ritos sumário e ordinário do Código de Processo Penal, mais especificamente julgados nos Juizados da Mulher. ${ }^{32}$ Tal opção legislativa é justamente o ponto de partida da problemática que se pretende analisar no presente estudo. Para tanto, neste capítulo, deve-se realizar $(i)$ o exame crítico da política criminal que fundamentou a inaplicabilidade da Lei $\mathrm{n}^{\circ}$ 9.099/95 (ii) em conjunto com a consolidação de tal entendimento por meio do quanto fixado pelo Supremo Tribunal Federal e pelo Superior Tribunal de Justiça.

\subsection{Exame crítico da política criminal adotada}

Inicialmente, deve-se esclarecer que a Lei $n^{\circ}$ 9.099/95 insere-se em um contexto de reforma do judiciário enquanto poder marcado pela morosidade e sobrecarga de processos ${ }^{33}$. Seguindo a disposição contida no artigo 98, I, da Constituição Federal, os Juizados Especiais, orientados para oralidade, economia processual e informalidade, foram, em um primeiro momento, bem recepcionados em razão de seguirem preceitos minimalistas voltados para a despenalização, o que significaria um avanço na política criminal brasileira. ${ }^{34}$

Nesse contexto, os Juizados Especiais Criminais passaram a ser competentes para julgar as infrações penais definidas pela Lei como de menor potencial ofensivo e, conforme o modelo de justiça consensual, para buscar solução voltada à conciliação, transação penal ou suspensão condicional do processo. Tais medidas alternativas ao processo penal e à pena privativa de liberdade são denominadas despenalizadoras: a primeira é a conciliação que, nas infrações de menor potencial ofensivo de iniciativa privada ou pública, condicionada à

\footnotetext{
${ }^{32}$ MACHADO, Érica Babini Lapa do Amaral e MELLO, Marília Montenegro Pessoa. O movimento social, o efeito simbólico e a estratégia desperdiçada: uma contribuição criminológica ao movimento LGBT a partir da Lei Maria da Penha in SANTIGO, Nestor Eduardo Araruna; BORGES, Paulo César Corrêa; PEREIRA, Cláudio José Langroiva (Org.). Direito Penal e Criminologia. Florianópolis: FUNJAB, 2013, pp. 592-620.

${ }^{33}$ MEDEIROS, Carolina Salazar l'Armée Queiroga de e MELLO, Marília Montenegro Pessoa de. Entre a "renúncia" e a intervenção penal no crime de violência doméstica contra a mulher in SANTIGO, Nestor Eduardo Araruna; BORGES, Paulo César Corrêa; SOUZA, Claudio Macedo de. (Org.). Direito penal, processo penal e constituição. Florianópolis: CONPENDI, 2014, pp. 488-514.

${ }^{34}$ Ibid., pp. 488-514.
} 
Rio de Janeiro. Ano 15. Volume 22. Número 3. Setembro a Dezembro de 2021

Periódico Quadrimestral da Pós-Graduação Stricto Sensu em Direito Processual da UERJ

Patrono: José Carlos Barbosa Moreira (in mem.). ISSN 1982-7636. pp. 631-655 www.redp.uerj.br

representação, gera a extinção da punibilidade do agente quando há composição civil (artigo 74, parágrafo único); a segunda é a transação penal que ocorre quando não há composição civil ou nos casos de ação penal pública incondicionada, incidindo a aplicação imediata das penas restritivas de direito ou da pena de multa (artigo 76); a terceira é a suspensão condicional do processo que permite, nos crimes cuja pena mínima não seja superior a um ano, a suspensão do processo por um período de dois a quatro anos. ${ }^{35}$

Após o regozijo inicial com a Lei $\mathrm{n}^{\circ}$ 9.099/95, não se esperava que os Juizados Especiais Criminais acabariam tratando, de forma majoritária, a violência doméstica contra a mulher em todo o Brasil. Isso porque, até a Lei Maria da Penha, os crimes de lesão corporal de natureza leve, crimes contra a honra e de ameaça - os mais recorrentes nos casos de violência doméstica - eram enquadrados no conceito de infração de menor potencial ofensivo perfazendo cerca de $70 \%$ dos processos julgados nesses Juizados. ${ }^{36}$

Portanto, sob forte pressão dos movimentos feministas e de mulheres, acabou-se por consolidar a visão de que a brandura dos Juizados Especiais era incapaz de conter o aparente aumento dos casos de violência doméstica contra a mulher por impor padrões diversos daqueles estabelecidos na CEDAW e na Convenção de Belém do Pará. ${ }^{37}$

Nessa toada, a Lei Maria da Penha foi introduzida justamente para estabelecer relevante alteração nos códigos de interpretação, pois, para além das questões simbólicas, a exclusão da adjetivação da violência doméstica como infração de menor potencial ofensivo fez com que tais formas de agressão passassem a ser vistas como penalmente relevantes. Em outras palavras:

O principal argumento para a modificação introduzida pelo artigo 41 se funda em síntese, no que se denomina de banalização do crime praticado contra a mulher, decorrente da brandura da resposta penal proposta pela Lei 9.099/95, de modo que, afirma-se, além de não contribuir para a prevenção, a punição e erradicação da violência contra a mulher, tem

\footnotetext{
${ }^{35}$ MONTENEGRO, Marilia. Lei Maria da Penha: uma análise criminológico-crítica. $1^{\text {a }}$ ed., Rio de Janeiro: Revan, 2015, pp. 80-98.

${ }^{36}$ CAMPOS, Carmen Hein de; CARVALHO, Salo de. Violência doméstica e Juizados Especiais Criminais: análise a partir do feminismo e do garantismo. Revista Estudos Feministas, Florianópolis, vol. 14, n. 2, pp. 409-422, mai./ago., 2006, p. 412.

37 MEDEIROS, Carolina Salazar l'Armée Queiroga de e MELLO, Marília Montenegro Pessoa de. Entre a "renúncia" e a intervenção penal no crime de violência doméstica contra a mulher in SANTIGO, Nestor Eduardo Araruna; BORGES, Paulo César Corrêa; SOUZA, Claudio Macedo de. (Org.). Direito penal, processo penal e constituição. Florianópolis: CONPENDI, 2014, pp. 488-514.
} 
Revista Eletrônica de Direito Processual - REDP.

Rio de Janeiro. Ano 15. Volume 22. Número 3. Setembro a Dezembro de 2021

Periódico Quadrimestral da Pós-Graduação Stricto Sensu em Direito Processual da UERJ

Patrono: José Carlos Barbosa Moreira (in mem.). ISSN 1982-7636. pp. 631-655

www.redp.uerj.br

contribuído para exacerbar o sentimento de impunidade e alimentar o preconceito e a discriminação contra as mulheres na sociedade brasileira. ${ }^{38}$

Nesse sentido, diante da conjuntura existente, haveria uma lógica em se negar a aplicação dos mecanismos tradicionais da Lei $\mathrm{n}^{\circ}$ 9.099/95, não cabendo, portanto, as medidas despenalizadoras tal qual disposto pelo artigo 41 da Lei Maria da Penha.

\subsection{O entendimento consolidado pelo Supremo Tribunal Federal e pelo Superior Tribunal de Justiça}

Diante das inovações no âmbito processual penal introduzidas pela Lei Maria da Penha, não tardou para que as alterações fossem levadas à apreciação do Supremo Tribunal Federal. No dia 9 de fevereiro de 2012, foram julgados em Plenário a Ação Direta de Inconstitucionalidade (ADI) n 4.424 e a Ação Declaratória de Constitucionalidade (ADC) n 19 , ambas sob relatoria do Ministro Marco Aurélio.

A ADI n 4.424 foi julgada procedente para dar intepretação conforme aos artigos 12, inciso I, 16 e 41 da Lei $n^{\circ} 11.340 / 2006$, assentando a natureza incondicionada da ação penal em caso de crime de lesão corporal praticado contra a mulher no ambiente doméstico, nos termos do voto do relator ${ }^{39}$.

A título elucidativo da linha argumentativa da maioria, a Ministra Rosa Weber acompanhando o voto do Relator também deu interpretação conforme ao artigo 41 da Lei

\footnotetext{
${ }^{38}$ MACHADO, Érica Babini Lapa do Amaral e MELLO, Marília Montenegro Pessoa. O movimento social, o efeito simbólico e a estratégia desperdiçada: uma contribuição criminológica ao movimento LGBT a partir da Lei Maria da Penha in SANTIGO, Nestor Eduardo Araruna; BORGES, Paulo César Corrêa; PEREIRA, Cláudio José Langroiva (Org.). Direito Penal e Criminologia. Florianópolis: FUNJAB, 2013, pp. 592-620.

39 "Procede às inteiras o pedido formulado pelo procurador-geral da República, buscando-se o empréstimo de concretude maior à Constituição Federal. Deve-se dar interpretação conforme à Carta da República aos arts. 12, I; 16; e 41 da Lei 11.340/2006 - Lei Maria da Penha - no sentido de não se aplicar a Lei 9.099/1995 aos crimes glosados pela lei ora discutida, assentando-se que, em se tratando de lesões corporais, mesmo que consideradas de natureza leve, praticadas contra a mulher em âmbito doméstico, atua-se mediante ação penal pública incondicionada. [...] Representa a Lei Maria da Penha elevada expressão da busca das mulheres brasileiras por igual consideração e respeito. Protege a dignidade da mulher, nos múltiplos aspectos, não somente como um atributo inato, mas como fruto da construção realmente livre da própria personalidade. Contribui com passos largos no contínuo caminhar destinado a assegurar condições mínimas para o amplo desenvolvimento da identidade do gênero feminino." (BRASIL. Supremo Tribunal Federal, Ação Direta de Inconstitucionalidade $n^{\circ}$ 4.424, Relator Ministro Marco Aurélio, Plenário, data do julgamento: 9 de fevereiro de 2012. Disponível em: < http://redir.stf.jus.br/paginadorpub/paginador.jsp?docTP=TP\&docID=6393143>. Acesso em março de 2019).
} 
Maria da Penha, sem redução de texto, no sentido de fixar que aos crimes praticados com violência doméstica e familiar contra a mulher não se aplica a Lei $\mathrm{n}^{\circ}$ 9.099/95 independentemente da pena prevista, "inclusive o disposto no seu art. 88, e que, consequentemente, o crime de lesões corporais leves, quando praticado com violência doméstica e familiar contra a mulher, processa-se mediante ação penal pública incondicionada" sob a fundamentação de que ${ }^{40}$ :

Ao desconsiderar o propósito da legislação em exame - escorada em compromissos assumidos no texto da Constituição Republicana e em tratados internacionais - de afirmar um sistema de persecução e punição minimamente eficaz para o tipo específico de violência que é a violência doméstica direcionada contra a mulher, a interpretação do art. 41 da Lei 11.340/2006 que assim conclui resulta em falta para com a obrigação do Estado de atuar positivamente na realização do seu objetivo.

Dentre as argumentações favoráveis à ação penal pública incondicionada, apesar da afirmação de que o julgamento se deu com base na realidade da violência de gênero, é possível encontrar referências à "fragilidade feminina" decorrer da ação penal" ${ }^{\prime 2}$.

Somente no voto vencido do Ministro Cezar Peluso, fugiu-se do senso comum ao se asseverar ser consequência do respeito aos direitos humanos a atenção à vontade das mulheres, sujeitos capazes de autodeterminação e, portanto, da possibilidade de escolha sobre o seu destino ${ }^{43}$ :

Por outro lado - e esse o aspecto que mais me preocupa, mais me incomoda, que mais me atormenta, e esta é a razão pela qual estou tomando esta postura -, acho que nós, do Judiciário, estamos assumindo todos esses riscos, e assumindo-os com perda da visão da situação familiar. Nós estamos concentrados na situação da mulher, que merece, evidentemente, todas as nossas preocupações, merece toda a proteção do ordenamento jurídico. Isso é coisa indiscutível. Mas assim o legislador, como o constituinte levaram em consideração, como valores, que têm que ser de algum modo compatibilizados, a necessidade da proteção da condição da mulher e a necessidade da manutenção da situação familiar, em que está envolvida não apenas a condição da mulher ou a condição do parceiro, mas

\footnotetext{
${ }^{40}$ BRASIL. Supremo Tribunal Federal, Ação Direta de Inconstitucionalidade $n^{\circ} 4.424 . . .$, pp. 41-9.

${ }^{41}$ Conforme concordam a Ministra Cármen Lúcia e o Ministro Ayres Britto durante o voto proferido pelo Ministro Ayres Britto (BRASIL. Supremo Tribunal Federal, Ação Direta de Inconstitucionalidade $n^{\circ} 4.424 \ldots$, p. 79).

${ }^{42}$ Nos termos do voto do Ministro Ricardo Lewandowski (BRASIL. Supremo Tribunal Federal, Ação Direta de Inconstitucionalidade $n^{\circ} 4.424 \ldots$, p. 67).

${ }^{43}$ BRASIL. Supremo Tribunal Federal, Ação Direta de Inconstitucionalidade $n^{\circ} 4.424 \ldots$, p. 93.
} 
também filhos, netos, outros parentes, e que constituem elemento fundamental na mecânica da sociedade.

Por estas razões, que representam pouco menos que discordância intelectual com a postura adotada pela douta maioria, vou votar vencido para que meu voto fique marcado como advertência para o legislador. E faço-o na expectativa, e mais do que expectativa, na grande esperança de que a douta maioria tenha acertado mais uma vez.

Sob raciocínio semelhante, o Plenário do Supremo Tribunal Federal, por unanimidade, julgou procedente $\mathrm{ADC} \mathrm{n}^{\mathrm{o}} 19$ para declarar a constitucionalidade dos artigos $1^{\circ}, 33$ e 41 da Lei ${ }^{\circ} 11.340 / 2006$, nos termos do voto do relator ${ }^{44}$. Em consonância com o entendimento fixado, a Ministra Carmen Lúcia asseverou que “[...] não tivesse a experiência com a aplicação da Lei 9.099/1995 se mostrado inadequada ou insuficiente para lidar com a violência praticada no âmbito familiar, e não teria o legislador inserido, na Lei 11.340/2006, o seu art. 41."45.

A despeito da clareza de tais precedentes no sentido de assentar a constitucionalidade do artigo 41 da Lei Maria da Penha, sem qualquer ressalva e, por consequência, a incompatibilidade entre os crimes praticados com violência familiar e a Lei no 9.099/95 como um todo, ainda remanesceram discussões acerca da inaplicabilidade do artigo $89^{46}$ da Lei dos Juizados Especiais Criminais que trata sobre a suspensão condicional do processo ${ }^{47}$. Com isso, em 2015, o Superior Tribunal de Justiça editou a Súmula n 536 e sedimentou a questão ao fixar que "[a] suspensão condicional do processo a transação penal não se aplicam na hipótese de delitos sujeitos ao rito da Lei Maria da Penha" ${ }^{\text {48 }}$ tornando-se inegável a constitucionalidade da proibição da aplicação da Lei no 9.099/95.

\footnotetext{
${ }^{44}$ BRASIL. Supremo Tribunal Federal, Ação Declaratória de Constitucionalidade $n^{\circ} 19$, Relator Ministro Marco Aurélio, Plenário, data do julgamento: 9 de fevereiro de 2012. Disponível em: < http://redir.stf.jus.br/paginadorpub/paginador.jsp?docTP=TP\&docID=5719497>. Acesso em março de 2019.

${ }^{45}$ BRASIL. Supremo Tribunal Federal, Ação Declaratória de Constitucionalidade n ${ }^{\circ} 19 \ldots . .$. p. 28.

${ }^{46}$ Art. 89. Nos crimes em que a pena mínima cominada for igual ou inferior a um ano, abrangidas ou não por esta Lei, o Ministério Público, ao oferecer a denúncia, poderá propor a suspensão do processo, por dois a quatro anos, desde que o acusado não esteja sendo processado ou não tenha sido condenado por outro crime, presentes os demais requisitos que autorizariam a suspensão condicional da pena (art. 77 do Código Penal). [...]

${ }^{47}$ Isso se deve ao fato de o artigo 89 ser visto como instrumento "à parte" no âmbito da Lei dos Juizados Especiais Criminais justamente por estabelecer critérios específicos e diversos daqueles que norteiam a racionalidade da Lei ${ }^{\circ}$ 9.099/95.

${ }^{48}$ BRASIL. Superior Tribunal de Justiça, Súmula 536, Terceira Seção, julgado em 10.06.2015, DJe 15.06.2016. Disponível em:

https://scon.stj.jus.br/SCON/sumanot/toc.jsp?livre=(sumula\%20adj1\%20\%27536\%27).sub.\#TIT1TEMA0 $>$. Acesso em junho de 2019.
} 


\section{A OPÇÃO LEGISLATIVA À LUZ DO PROCESSO PENAL CONSENSUAL E AS CRÍTICAS CABÍVEIS}

Ante a clara opção legislativa adotada pela Lei Maria da Penha e reafirmada pelos tribunais superiores, no sentido de afastar a aplicação dos institutos consensuais da Lei $\mathrm{n}^{\circ}$ 9.099/95, busca-se, inicialmente, analisar a referida escolha à luz do que vem a ser processo penal consensual e, posteriormente, tecer as devidas críticas.

\subsection{Processo penal consensual e Lei $n^{0} 9.099 / 95$}

Para melhor delimitar o que se entende por processo penal consensual, emprega-se a terminologia de TULKENS e KERCHOVE, que classificam os modelos de justiça criminal em (i) impositiva; (ii) participativa; (iii) consensual e (iv) negociada. Entre os dois extremos justiça impositiva e negociada -, há as formas intermediárias, que constituem uma gradação de tons ${ }^{49}$.

A justiça impositiva considera a infração penal como violação exclusiva do interesse público, de modo que a investigação, o processo e a condenação cabem exclusivamente ao Estado, cujas decisões unilaterais são impostas de maneira autoritária aos seus destinatários $^{50}$. Os referidos autores ressalvam que provavelmente nenhum sistema tenha consagrado um modelo de justiça impositiva puro, mas sim combinado esse com o modelo que denominam de justiça participativa, pelo qual o Direito Penal perde sua característica exclusivamente estatal e unilateral, passando a admitir, em graus diversos, a participação ativa de agentes privados no trâmite processual (seja a do autor do fato, da vítima ou de outra pessoa $)^{51}$.

O terceiro modelo de justiça penal, chamado justiça consensual, acentua o papel ativo tanto da vítima quanto do autor da infração. Nesse modelo, há espaço para aceitação, ou abstenção, ou recusa. Como exemplos, pode-se citar a renúncia à interposição de recursos; a transação penal; as penas restritivas de direitos e o sursis processual, os quais são

\footnotetext{
49 TULKENS, Françoise; KERCHOVE, M. van de. La Justice pénale. Justice imposée, justice participative, justice consensuelle ou justice négociée, 1996, RDPC, 455, pp. 445-7.

${ }^{50}$ Cita-se como exemplo o procedimento inquisitório puro no qual não há qualquer participação ativa do réu, que não possui voz a não ser para confessar, desenvolvendo-se a instrução em segredo. (Ibid., pp. 447-8).

${ }^{51}$ Menciona-se como exemplo a ação penal privada e o direito de defesa do acusado. (Ibid., p. 448).
} 
Rio de Janeiro. Ano 15. Volume 22. Número 3. Setembro a Dezembro de 2021

Periódico Quadrimestral da Pós-Graduação Stricto Sensu em Direito Processual da UERJ

Patrono: José Carlos Barbosa Moreira (in mem.). ISSN 1982-7636. pp. 631-655 www.redp.uerj.br

geralmente submetidos ao consentimento do autor da infração ${ }^{52}$.

Por fim, tem-se o modelo de justiça negociada, no qual há poder de discussão com concessões recíprocas aptas a afetar, ao menos parcialmente, o conteúdo dessas propostas a fim de se obter um acordo real negociado ${ }^{53}$. Importa mencionar que tal modelo não pode ser reduzido a simples “contratos de adesão", como por exemplo em procedimentos de mediação e na plea bargaining ${ }^{54}$.

A despeito desse breve panorama, para fins do presente estudo, importa focar especialmente no modelo de justiça penal consensual de TULKENS e KERCHOVE uma vez que a Lei $n^{\circ}$ 9.099/95 recepcionou tal modelo ${ }^{55}$. Ao fazer isso, a Lei dos Juizados Especiais Criminais "apresenta uma verdadeira modificação não só no direito processual penal brasileiro, como também no Direito Penal, em especial na teoria da pena." ${ }^{\text {. }}$. Isso se deve não somente às alterações introduzidas no âmbito do rito processual a ser seguido em tais varas, mas, principalmente, por meio das ditas medidas despenalizadoras, quais sejam: $(i)$ conciliação; (ii) transação penal e (iii) suspensão condicional do processo.

A conciliação apresenta-se como a principal "esperança de um novo modelo" 57 de justiça penal uma vez que busca a minoração de conflitos por meio, principalmente, da reparação dos danos das partes envolvidas e, não, somente visando a punição. No bojo da Lei dos Juizados Especiais Criminais, tal alternativa só é cabível nos termos de seu artigo $74^{58}$. Trata-se de um momento entre a vítima e o autor do fato, intermediado por um juiz ou conciliador, que visa a composição de um acordo entre as partes, em momento anterior à

\footnotetext{
52 TULKENS, Françoise; KERCHOVE, M. van de. La Justice pénale. Justice imposée, justice participative, justice consensuelle ou justice négociée, 1996, RDPC, 455, pp. 448-9.

${ }^{53}$ Ibid., pp. 449.

${ }^{54}$ Embora os autores não se refiram expressamente à justiça restaurativa, entendemos que, tal qual a mediação, também se insere nos procedimentos de justiça negociada em razão da liberdade existente no conteúdo das negociações. Nesse sentido também a posição de VINÍCIUS GOMES DE VASCONCELLOS (VASCONCELLOS, Vinícius Gomes de. Barganha e Justiça Criminal Negocial. $2^{\mathrm{a}}$ ed. Belo Horizonte: D’Plácido, 2018, pp. 56-7).

${ }^{55}$ GRINOVER, Ada Pellegrini; GOMES FILHO, Antônio Magalhães; FERNANDES, Antonio Scarance; GOMES, Luiz Flávio. Juizados especiais criminais: comentários à Lei 9.099 de 26.09.95. 4ª ed., São Paulo: Revista dos Tribunais, 2002, pp. 37-8.

${ }^{56}$ MONTENEGRO, Marilia. Lei Maria da Penha: uma análise criminológico-crítica. $1^{\text {a }}$ ed., Rio de Janeiro: Revan, 2015, p. 74.

${ }^{57}$ Ibid., pp. 89-98.

58 Art. 74. A composição dos danos civis será reduzida a escrito e, homologada pelo Juiz mediante sentença irrecorrível, terá eficácia de título a ser executado no juízo civil competente.

Parágrafo único. Tratando-se de ação penal de iniciativa privada ou de ação penal pública condicionada à representação, o acordo homologado acarreta a renúncia ao direito de queixa ou representação.
} 
existência de uma acusação formal. Caso seja frutífera a audiência de conciliação, extinguese a punibilidade antes mesmo do início da própria ação penal.

É claro que tal instituto não é imune de críticas ou problemas quando de sua aplicação prática $^{59}$. Não obstante, mostra-se como alternativa louvável que deve ser estimulada no âmbito penal justamente por evitar o uso reiterado e inconsequente de um direito penal que não cumpre suas funções declaradas e que, por vezes - como no caso da violência doméstica - , serve somente como instrumento simbólico ${ }^{60}$.

Por sua vez, a transação penal, prevista no artigo $76^{61}$ da Lei n ${ }^{\circ} 9.099 / 95$, trata-se, de modo simplificado, de uma verdadeira antecipação da pena, pois possibilita ao autor do fato a escolha entre ser denunciado e seguir o rito processual até a prolação de sentença ou o cumprimento antecipado da pena restritiva de direito ou de multa.

Por fim, a suspensão condicional do processo ou sursis processual, introduzida pelo artigo $89^{62}$ da Lei dos Juizados Especiais Criminais, evita o processo em si, suspendendo a própria ação por um período de prova, que pode variar de dois a quatro anos, em que o réu ao aceitar a proposta se compromete ao cumprimento de determinadas condições. Com isso, ao final de tal período, ocorre a extinção de punibilidade, sem o julgamento do mérito.

\subsection{Críticas à opção legislativa da Lei Maria da Penha}

Não se pretende negar que a Lei $n^{\circ}$ 9.099/95 apresenta falhas, em especial, com relação ao tratamento que acabou sendo conferido às situações de violência doméstica. Vale dizer que a opção legislativa, referendada pelo Supremo Tribunal Federal e pelo Superior

\footnotetext{
59 “O significado de conciliação, embora seja bastante cativante, é ainda ambíguo e indefinido, bem como qual seria delimitação do seu campo de aplicação. O movimento que busca a conciliação pode ser inicialmente dividido em dois eixos: o primeiro formado por aqueles que buscam a conciliação dentro do Direito Penal e o segundo, formado por aqueles que acreditam que nenhum tipo de conciliação pode ocorrer dentro do Direito Penal, sendo essa um substitutivo, mesmo que transitório, para o Direito Penal.” (Ibid., p. 92)

60 "São vários os motivos para a conciliação, reparação ou mediação serem tão discutidas na esfera penal, mas, sem dúvida, a razão mais forte é a demonstração do fracasso das funções declaradas do sistema penal, que, ao invés de resolver o problema da vítima, cria novas vítimas: os apenados. Também podem ser considerados motivos que colaboram para essa discussão, a frustração com as penas restritivas de direitos, que, na prática, não funcionam, já que nunca substituíram a pena privativa de liberdade, e a crescente preocupação com o tratamento penal e o processo penal dado à vítima." (Ibid., p. 92).

${ }^{61}$ Art. 76. Havendo representação ou tratando-se de crime de ação penal pública incondicionada, não sendo caso de arquivamento, o Ministério Público poderá propor a aplicação imediata de pena restritiva de direitos ou multas, a ser especificada na proposta. [...]

${ }^{62}$ Vide nota de rodapé 45 .
} 
Tribunal de Justiça, de inaplicabilidade dos institutos despenalizadores insculpidos na Lei $\mathrm{n}^{\mathbf{o}}$ 9.099/95 às hipóteses de violência doméstica e familiar contra a mulher teve por supedâneo a sua má aplicação nas varas dos Juizados Especiais Criminais em todo território nacional, em que processos eram resolvidos em lote, sem atenção a suas especificidades, e com a imposição de mero pagamento de cestas básicas a entidades assistenciais. ${ }^{63}$

Receia-se, por outro lado, que o clamor punitivo, externado pelos grupos de mulheres e feministas e divulgado pelos meios de comunicação, que desejava o retorno da pena privativa de liberdade por meio da vedação da aplicação da Lei dos Juizados Especiais Criminais aos casos de violência doméstica, possa gerar mais problemas do que soluções às mulheres ofendidas.

Isso porque a Lei Maria da Penha acabou por maximizar o caráter retributivo das penas e o caráter simbólico do Direito Penal ${ }^{64}$ baseado na crença de que leis mais severas possam mudar a consciência e a atitude relativamente à violência contra a mulher. Nesse sentido, o legislador ignorou por completo a violência estrutural e os seus condicionamentos, inseridos na maioria das vezes em contextos familiares, adotando um discurso simplesmente punitivo, procurando apenas atribuir a culpa a alguém. Assim, acabou estigmatizando os sujeitos envolvidos, oferecendo falsas soluções sem considerar o contexto doméstico e os anseios da vítima e afastando a possibilidade de diálogo entre a ofendida e o ofensor ao vedar a aplicação da Lei n ${ }^{\circ}$ 9.099/95.

Transcorrida mais de uma década desde a edição da Lei Maria da Penha, o discurso bradado pelos seus defensores está longe de se concretizar. Deveras, a opção legislativa, no que tange aos crimes de lesões corporais leves e de ameaça perpetrados por agentes primários (casos em que se aplicava anteriormente os institutos despenalizadores da Lei ${ }^{\circ}$ 9.099/95), tem redundado em aplicação de reprimenda de poucos meses de detenção, em regime aberto, com concessão de sursis. E para se obter essa punição - que não resolve o conflito - instaurase processo judicial carregado de formalidades e morosidade para chegar a termo.

\footnotetext{
${ }^{63}$ FERREIRA, Lucas César Costa. A justiça restaurativa no âmbito da violência doméstica e familiar contra a mulher: potencialidades e riscos a partir de uma perspectiva feminista. Revista Brasileira de Ciências Criminais, São Paulo, v. 26, n. 150, dez. 2018, p. 522. Adverte também o autor: "Essa resistência brasileira à solução dialógica, ao menos sob o viés normativo, como destaca Thiago Pierobom Ávila (2014), contraria a recomendação da OEA, que, no histórico caso Maria da Penha, condenou o Brasil a simplificar procedimentos judiciais penais e a estabelecer meios alternativos céleres e efetivos de solução de conflitos intrafamiliares, com observância do seu caráter grave e das consequências penais aplicadas.” (Op. cit., p. 523).

${ }^{64}$ Vide nota de rodapé 20.
} 
Não se olvide, ainda, que nesse caminho quase sempre é obstado qualquer canal de conciliação dos envolvidos, notadamente no âmbito cível, recusando-se no mais das vezes o réu de processo criminal a realizar acordos relativos a alimentos, guarda e visitas até que haja solução do feito criminal, com reflexos deletérios inclusive à prole.

Sumulando, o cenário legislativo atual pouco se compraz com o processo penal consensual e, outrossim, como pondera KARAM:

Quando se insiste em acusar da prática de um crime e ameaçar com uma pena o parceiro da mulher, contra a sua vontade, está se subtraindo dela, formalmente dita ofendida, seu direito e seu anseio a livremente se relacionar com aquele parceiro por ela escolhido. Isto significa negar-lhe o direito à liberdade de que é titular, para tratá-la como se coisa fosse, submetida à vontade dos agentes do Estado que, inferiorizando-a e vitimizando-a, pretendem saber o que seria melhor para ela, pretendendo punir o homem com quem ela quer se relacionar $[\ldots] .{ }^{65}$

Deste modo, diante da consolidação das disposições contidas na Lei Maria da Penha, que não superam o problema, resta agora encontrar alternativas dentro do próprio ordenamento jurídico, explorar suas medidas cíveis e de caráter preventivo e oferecer subsídios contrários ao discurso punitivo. Isso pois, conclui MONTENEGRO ${ }^{66}$ :

Conflitos oriundos de relações domésticas sempre existirão, em decorrência da própria convivência humana. Sua minoração deve passar, antes, pelo diálogo e a pela tentativa de conciliação e, jamais, iniciar-se pelas mãos do Direito Penal.

Por fim, não será através do Direito Penal que a mulher encontrará a proteção e a igualdade, pois a mudança de comportamento e de mentalidade vem através da educação e de ações preventivas. De tudo o que foi colocado até aqui, resta a conclusão principal que o modelo penal não é, em absoluto, o adequado para dirimir conflitos familiares e domésticos.

Nesse sentido, a despeito da opção legislativa consolidada pela Lei n ${ }^{\circ}$ 11.340/2006, aponta-se, especialmente, a conciliação como caminho adequado uma vez que "como os envolvidos se conhecem e os laços familiares não poderão ser rompidos, a conciliação pode apresentar uma resposta personalizada, atendendo aos anseios dos envolvidos, que possibilita, inclusive, restaurar laços afetivos. $" 67$.

\footnotetext{
${ }^{65}$ KARAM, Maria Lucia. Violência de gênero: o paradoxal entusiasmo pelo rigor penal. Boletim IBCCRIM, v. 14 , n. 168 , nov. 2006 , p. 7

${ }^{66}$ MONTENEGRO, Marilia. Lei Maria da Penha: uma análise criminológico-crítica. $1^{\text {a }}$ ed., Rio de Janeiro: Revan, 2015, p. 198.

${ }^{67}$ MONTENEGRO, Marilia. Lei Maria da Penha: uma análise criminológico-crítica. $1^{\mathrm{a}}$ ed., Rio de Janeiro: Revan, 2015, p. 97.
} 


\section{CONCLUSÕES}

Com o fito de corresponder aos anseios oriundos dos movimentos das mulheres e das feministas motivado pelo contexto histórico de violência de gênero e de cumprir a condenação do Estado brasileiro prolatada pela Corte Interamericana de Direitos Humanos, no caso Maria da Penha, foi promulgada, no ano de 2006, a Lei ${ }^{\circ}{ }^{11.340}$, conhecida pelo nome da vítima referida.

Além de inúmeras inovações materiais e processuais, vedou-se, neste diploma, a aplicação dos institutos despenalizadores da Lei $n^{\circ}$ 9.099/95, notadamente a conciliação, transação penal e suspensão condicional do processo, opção cuja constitucionalidade foi declarada pelo Supremo Tribunal Federal e pelo Superior Tribunal de Justiça.

Trata-se de situação posta que merece diversas críticas sobretudo por valorizar a aplicação de um direito penal simbólico e que não fornece soluções reais ao problema da violência doméstica. Desse modo, após a análise individual dos institutos despenalizadores, foram elaboradas críticas contundentes à tal opção legislativa no sentido de ensejar um despertar para a adoção de caminhos alternativos para a questão da violência doméstica inserida na perspectiva do processo penal consensual, especialmente, para o instituto da conciliação que melhor se adequaria ao contexto das relações domésticas e afetivas.

Conclui-se, portanto, pelo desacerto da Lei Maria da Penha, reafirmado pelos tribunais superiores brasileiro, ao vedar totalmente a aplicação da Lei ${ }^{\circ}$ 9.099/95 afastando qualquer possibilidade de um tratamento consensual e alinhado com a delicada realidade em que se insere a questão da violência doméstica.

\section{REFERÊNCIAS}

ALVES, Branca Moreira; PITANGUY, Jacqueline. O que é feminismo. Coleção Primeiros Passos. São Paulo: Abril Cultural/Brasiliense, 1981. 
ANDRADE, Vera Regina Pereira de. Sistema penal máximo x Cidadania mínima: códigos de violência na Era da globalização. Porto Alegre: Editora Livraria do Advogado, 2003.

BORIN, Thaisa Belloube. Violência doméstica contra a mulher: percepções sobre violência em mulheres agredidas. Dissertação de mestrado em Psicologia apresentada à Faculdade de Filosofia, Ciências e Letras de Ribeirão Preto da Universidade de São $\begin{array}{lllll}\text { Paulo. } & \text { Teses } & \text { USP. }\end{array}$ http://www.teses.usp.br/teses/disponiveis/59/59137/tde-30092008-

125835/publico/Thaisa.pdf > . Acesso em março de 2019.

BRASIL. Superior Tribunal de Justiça, Súmula 536, Terceira Seção, julgado em 10.06.2015, DJe 15.06.2016. Disponível em: < https://scon.stj.jus.br/SCON/sumanot/toc.jsp?livre=(sumula\%20adj1\%20\%27536\% 27).sub.\#TIT1TEMA0>. Acesso em junho de 2019.

BRASIL. Supremo Tribunal Federal, Ação Declaratória de Constitucionalidade $n^{o} 19$, Relator Ministro Marco Aurélio, Plenário, data do julgamento: 9 de fevereiro de 2012. Disponível em: http://redir.stf.jus.br/paginadorpub/paginador.jsp?docTP=TP\&docID=5719497> . Acesso em março de 2019.

BRASIL. Supremo Tribunal Federal, Ação Direta de Inconstitucionalidade $n^{\circ} 4.424$, Relator Ministro Marco Aurélio, Plenário, data do julgamento: 9 de fevereiro de 2012. Disponível em: http://redir.stf.jus.br/paginadorpub/paginador.jsp?docTP=TP\&docID=6393143> . Acesso em março de 2019.

BUTLER, Judith. Problemas de gênero: feminismo e subversão da identidade. Tradução Renato Aguiar. Rio de Janeiro: Civilização Brasileira, 2003.

CAMPOS, Carmen Hein de; CARVALHO, Salo. Tensões atuais entre a criminologia feminista e a criminologia crítica: a experiência brasileira. In: CAMPOS, Carmen Hein de (Org.). Lei Maria da Penha Comentada em uma perspectiva jurídicofeminista. Rio de Janeiro: Lumen Juris, p.143-172, 2011. 
CAMPOS, Carmen Hein de; CARVALHO, Salo de. Violência doméstica e Juizados Especiais Criminais: análise a partir do feminismo e do garantismo. Revista Estudos Feministas, Florianópolis, vol. 14, n. 2, pp. 409-422, mai./ago., 2006.

FERREIRA, Lucas César Costa. A justiça restaurativa no âmbito da violência doméstica e familiar contra a mulher: potencialidades e riscos a partir de uma perspectiva feminista. Revista Brasileira de Ciências Criminais, São Paulo, v. 26, n. 150, p. 515538., dez. 2018.

GRINOVER, Ada Pellegrini; GOMES FILHO, Antônio Magalhães; FERNANDES, Antonio Scarance; GOMES, Luiz Flávio. Juizados especiais criminais: comentários à Lei 9.099 de 26.09.95. $4^{\mathrm{a}}$ ed., São Paulo: Revista dos Tribunais, 2002.

GERHARD, Ute. Sobre a liberdade, igualdade e dignidade das mulheres: o direito “diferente” de Olympe de Gouges. In: BONACCHI, Gabriela; groppi, Angela (Orgs). O dilema da cidadania: direitos e deveres das mulheres. São Paulo: Editora da Universidade Estadual Paulista, 1995.

HASSEMER, Winfried. Derecho Penal Simbólico y protección de Bienes Jurídicos. Tradução livre. Santiago: Editorial Jurídica Conosur, 1995.

KARAM, Maria Lucia. Violência de gênero: o paradoxal entusiasmo pelo rigor penal. Boletim IBCCRIM, v. 14, n. 168, p. 6-7, nov. 2006.

MACHADO, Érica Babini Lapa do Amaral e MELLO, Marília Montenegro Pessoa. O movimento social, o efeito simbólico e a estratégia desperdiçada: uma contribuição criminológica ao movimento LGBT a partir da Lei Maria da Penha in SANTIGO, Nestor Eduardo Araruna; BORGES, Paulo César Corrêa; PEREIRA, Cláudio José Langroiva (Org.). Direito Penal e Criminologia. Florianópolis: FUNJAB, pp. 592620, 2013.

MESQUITA, Luisa Angélica Mendes. Violência de gênero e direito penal: tipificação do feminicídio e possíveis respostas penais. Revista Eletrônica de Direito Penal e Política Criminal-UFRGS, v. 6, n. 2, dezembro de 2018.

MEDEIROS, Carolina Salazar 1'Armée Queiroga de e MELLO, Marília Montenegro Pessoa de. Entre a "renúncia" e a intervenção penal no crime de violência doméstica contra a mulher in SANTIGO, Nestor Eduardo Araruna; BORGES, Paulo César Corrêa; 
Rio de Janeiro. Ano 15. Volume 22. Número 3. Setembro a Dezembro de 2021

Periódico Quadrimestral da Pós-Graduação Stricto Sensu em Direito Processual da UERJ

Patrono: José Carlos Barbosa Moreira (in mem.). ISSN 1982-7636. pp. 631-655

SOUZA, Claudio Macedo de. (Org.). Direito penal, processo penal e constituição.

Florianópolis: CONPENDI, pp. 488-514, 2014.

MONTENEGRO, Marilia. Lei Maria da Penha: uma análise criminológico-crítica. $1^{\mathrm{a}}$ ed., Rio de Janeiro: Revan, 2015.

SANTOS, Cecília MacDowell. Da delegacia da Mulher à Lei Maria da Penha. Absorção/tradução de demandas feministas pelo Estado. Revista Crítica de Ciências Sociais, $\mathrm{n}^{\circ} 89,2010$.

SANTOS, Cláudia Cruz. Violência doméstica e mediação penal: uma convivência possível?. Revista de Estudos Criminais, Porto Alegre, v. 11, n. 49, p. 7-23., abr./jun. 2013.

TULKENS, Françoise; KERCHOVE, M. van de. La Justice pénale. Justice imposée, justice participative, justice consensuelle ou justice négociée, $R D P C, 455,1996$.

VASCONCELLOS, Vinícius Gomes de. Barganha e Justiça Criminal Negocial. $2^{\mathrm{a}}$ ed. Belo Horizonte: D’Plácido, 2018. 